\title{
Effectiveness and Safety of Bupropion in Children and Adolescents with Depressive Disorders: A Retrospective Chart Review
}

\author{
Kukju Kweon", Hyo-Won Kim² \\ ${ }^{1}$ Department of Psychiatry, Ulsan University Hospital, University of Ulsan College of Medicine, Ulsan, ${ }^{2}$ Department of Psychiatry, Asan Medical \\ Center, University of Ulsan College of Medicine, Seoul, Korea
}

\begin{abstract}
Objective: This study aimed to investigate the effectiveness and safety of bupropion extended-release for the treatment of depressive disorder in children and adolescents.

Methods: This was a 12-week, retrospective chart review of bupropion, which included 127 youth (age, $15.3 \pm 2.3$ years; 66 boys) with depressive disorders (105 with major depressive disorder, 14 with dysthymia, 11 with adjustment disorder with depressed mood, and seven with depressive disorder not otherwise specified). Illness severity at baseline and at the 4th, 8th, and 12th weeks was retrospectively scored using the Clinical Global Impressions-Depression-Severity (CGI-Depression-S) and/or Clinical Global Impressions-Depression-Improvement (CGI-Depression-I).

Results: The mean dose of bupropion was $180.0 \pm 52.6$ (range, 75-300) mg/day and the mean duration $33.9 \pm 53.1$ (range, 7-295) weeks. The CGI-Depression-S scores were significantly decreased over 12 weeks $(\mathrm{F}=132.125, p<$ 0.001 , partial $\eta^{2}=0.508$ ). Fifty-eight subjects $(45.7 \%)$ were determined to be responders at 12 weeks (defined by a CGI-Depression-I score $\leq 2)$. Forty-six patients $(36.2 \%$ ) discontinued bupropion before the 12 weeks (19 due to adverse events, 15 due to poor effectiveness, three due to referral to other clinics, and nine due to follow-up loss for unknown reasons). Overall, bupropion was well tolerated. The most common adverse event was irritability ( $\mathrm{n}=$ $12,9.4 \%)$, which resolved spontaneously in eight subjects or after drug discontinuation in four subjects.

Conclusion: Our results provide preliminary evidence of the effectiveness and safety of bupropion in children and adolescents with depressive episodes. Large, prospective, placebo-controlled studies are needed to confirm these findings.
\end{abstract}

KEY WORDS: Bupropion; Depressive disorder; Child, Adolescent; Treatment outcome; Drug-related side effects and adverse reactions.

\section{INTRODUCTION}

Although $1 \%$ to $2 \%$ of children and $5 \%$ of adolescents have depressive disorder, treatment options for pediatric depression are limited [1]. Only two antidepressants, fluoxetine and escitalopram, were approved for depression in youth by the United States Food and Drug Administration (FDA), and the effectiveness of other antidepressants has not been proven for pediatric depression. Furthermore, the debate on antidepressant-emergent

Received: April 12, 2018/ Revised: July 12, 2018

Accepted: August 14, 2018

Address for correspondence: Hyo-Won Kim

Department of Psychiatry, Asan Medical Center, University of

Ulsan College of Medicine, 88 Olympic-ro 43-gil, Songpa-gu,

Seoul 05505, Korea

E-mail: shingubi@amc.seoul.kr

ORCID: https://orcid.org/0000-0002-8744-5138 mood switch (AEMS) is discouraging the use of antidepressants in youth [1].

Bupropion was approved in 1989 by the FDA for the treatment of depression in adults [2] and is widely prescribed $[3,4]$. In studies conducted in adults, some patients who were resistant to selective serotonin reuptake inhibitors (SSRIs) responded well to bupropion [5], and bupropion is reported to have a lower AEMS rate than other antidepressants [6]. These results suggested that bupropion could be an alternative treatment option for pediatric depression.

However, the effectiveness and safety of bupropion has been rarely studied in pediatric populations. Only two small, open-label studies on youth with depression and one open-label trial on adolescents with both depression and attention-deficit/hyperactivity disorder (ADHD) have examined the effectiveness of bupropion [7-9]. Therefore,

(ㄷ) This is an Open-Access article distributed under the terms of the Creative Commons Attribution Non-Commercial License (http://creativecommons.org/licenses/by-nc/4.0) which permits unrestricted non-commercial use, distribution, and reproduction in any medium, provided the original work is properly cited. 
there is insufficient evidence regarding the use of bupropion in pediatric depression. Thus, we aimed to investigate the effectiveness and safety of bupropion for depressive disorder in youth.

\section{METHODS}

\section{Subjects}

This study was approved by the Institutional Review Board of Asan Medical Center, Seoul, Korea (2016-0141). We retrospectively reviewed the medical records of 127 children and adolescents who were treated with bupropion extended-release from January 2010 to December 2015 at the Department of Psychiatry of Asan Medical Center. The inclusion criteria were as follows: 1) age of 6 to 18 years; 2) diagnosis of major depressive disorder (MDD), dysthymia, adjustment disorder with depressive mood, or depressive disorder not otherwise specified (NOS) defined by the Diagnostic and Statistical Manual of Mental Disorders, 5th edition (DSM-5); and 3) having received bupropion treatment and evaluation at least once after the first administration of bupropion. Subjects were excluded based on any of the following criteria: 1 ) intelligence quotient $(\mathrm{IQ}),<70 ; 2)$ past and/or current history of psychotic, organic mental, or autism spectrum disorder; 3) presence of neurological disorders; 4) sensory impairments; and 5) concomitant use of another antidepressant, mood stabilizer, or antipsychotic (doses > $100 \mathrm{mg}$ of chlorpromazine or equivalent [10] for minimizing their effects on mood symptoms and adverse events.

\section{Diagnosis and Clinical Characteristics}

Two independent child psychiatrists (H.W.K. and K.K) retrospectively reviewed each subject's medical record and confirmed the diagnoses of depressive and comorbid psychiatric disorders $(\kappa=0.62-0.88)$ according to the DSM- 5 criteria. Additionally, we obtained information on age, gender, weight, IQ, socioeconomic status, previous history of suicide attempt, family history of psychiatric disorders, and concomitant non-pharmacological treatment. These data were already included in the medical records, entered by a board-certified child psychiatrist (H.W.K.) based on interviews with patients and their parents.

\section{Effectiveness and Safety of Bupropion}

To assess bupropion effectiveness, the Clinical Global Impressions-Depression-Severity (CGI-Depression-S) and Clinical Global Impressions-Depression-Improvement (CGI-Depression-I) scores [11,12] were determined by two child psychiatrists. In subjects with comorbid ADHD, the CGI scores for ADHD (CGI-ADHD-S and CGI-ADHD-I) were separately rated. One psychiatrist (H.W.K) who was involved with the treatment and another who was not (K.K.) independently rated the CGI. Discrepancies between the reviewers were discussed and resolved by consensus. The CGI-Depression-S and CGI-ADHD-S scores were obtained at baseline and the CGI- Depression-S, CGI-ADHD-S, CGI-Depression-I, and CGI-ADHD-I scores at the 4 th, 8 th, and 12 th weeks $(\kappa=$ 0.90). Treatment response was defined as a CGIDepression-I score of $\leq 2$ by the 12 th week of treatment. Safety was assessed at each visit based on spontaneous reports from the patients or their parents. AEMS was determined based on Goldberg and colleagues' criteria [13].

\section{Statistical Analyses}

Statistical analyses were performed using SPSS (version 22.0; IBM Co., Armonk, NY, USA). A significance level of 0.05 was used. The changes in CGI-Depression-S scores over time (4th, 8th, and 12th weeks) were analyzed using repeated measures ANOVA and a mixed-effect model for repeated measures adjusting for change in CGI-ADHD-S scores. Last observation carried forward (LOCF) imputation was used for patients who did not complete the treatment period. Demographic characteristics and psychiatric comorbidities were compared between responders and non-responders using the chi-squared or Fisher's exact test (categorical variables) and Student's $t$ test (continuous variables).

\section{RESULTS}

A cohort of 127 subjects was enrolled and analyzed in this study with a mean age of $15.3 \pm 2.3$ years (range, 8 18 years), mean IQ of $99.8 \pm 15.7$ (range, $70-139$ ), and male predominance $(n=66,52.0 \%)$. Full-scale IQ data were available for 102 of the 127 subjects and there was no significant difference in the missing-data rate between responders and non-responders $(19.0 \%$ vs. $20.3 \%)$. Fifty-one (40.2\%) subjects had family history of psychi- 
atric disorders and 19 (15.0\%) had previous history of suicide attempt. One hundred and five subjects (82.7\%) were diagnosed with MDD, 14 (11.0\%) with dysthymia, $11(8.7 \%)$ with adjustment disorder with depressive mood, and seven (5.5\%) with depressive disorder NOS.

The mean duration of bupropion treatment was $33.9 \pm$ 53.0 weeks (range, $7-295$ weeks). The mean dose of bupropion was $180.0 \pm 52.6 \mathrm{mg} /$ day (range, 75-300 $\mathrm{mg} /$ day) and the mean dose per weight was $3.0 \pm 1.6$ $\mathrm{mg} / \mathrm{kg} /$ day (range, $1.3-9.9 \mathrm{mg} / \mathrm{kg} /$ day). The most frequent comorbid diagnoses were ADHD ( $n=43,33.9 \%)$, followed by anxiety $(n=24,18.9 \%)$, oppositional defiant or conduct $(n=19,15.0 \%)$, tic $(n=13,10.2 \%)$, somatoform ( $n=6,4.7 \%)$, eating ( $n=5,3.9 \%$ ), post-traumatic stress $(n=4,3.1 \%)$, and elimination $(n=1,0.8 \%)$ disorders.

Figure 1 shows the mean scores obtained from the repeated measures ANOVA of the CGI-Depression-S scores at baseline and at each follow-up point. In the entire sample, the CGI-Depression-S scores were significantly decreased during the 12-week treatment period $(\mathrm{F}=$ 132.192, $p<0.001$, partial $\left.\eta^{2}=0.514\right)$. In subjects without comorbid ADHD ( $\mathrm{n}=84$ ), the CGl-Depression-S scores were significantly decreased $(\mathrm{F}=74.619, p<$ 0.001, partial $\left.\eta^{2}=0.473\right)$. In subjects with comorbid $\operatorname{ADHD}(\mathrm{n}=43)$, both the CGI-Depression-S ( $\mathrm{F}=51.326, p$ $<0.001$, partial $\left.\eta^{2}=0.550\right)$ and CGI-ADHD-S scores $(\mathrm{F}=$ 54.280, $p<0.001$, partial $\eta^{2}=0.576$ ) were significantly decreased. When we performed mixed-effect model analyses adjusting for the change in CGI-ADHD-S scores at each visit from baseline, the change in the

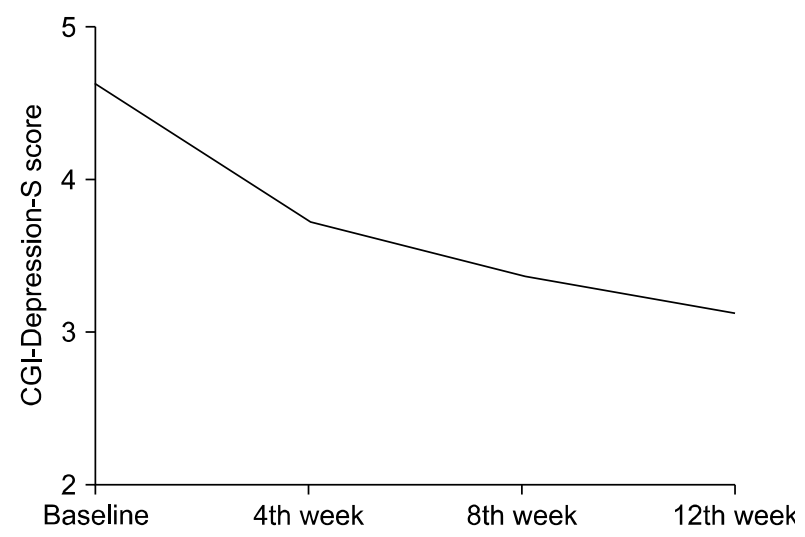

Fig. 1. The Clinical Global Impressions-Depression-Severity (CGIDepression-S) scores were significantly decreased during the 12 week trial $\left(F=132.192, p<0.001\right.$, partial $\left.\eta^{2}=0.514\right)$.
CGI-Depression-S score was still significant at the 4th $(\mathrm{F}=$ 56.570, $p<0.001$, partial $\left.\eta^{2}=0.586\right)$, 8th $(\mathrm{F}=73.855, p$ $<0.001$, partial $\left.\eta^{2}=0.687\right)$, and 12th week $(F=76.030$, $p<0.001$, partial $\left.\eta^{2}=0.655\right)$.

Among the 127 subjects, 58 (45.7\%) were considered responders at the 12-week follow up (defined by a CGI-Depression-I score $\leq 2$ ). Table 1 compares the clinical characteristics of responders to those of nonresponders. Responders showed higher rate of previous history of suicide attempt ( $p=0.006)$.

Forty-six participants (36.2\%) discontinued bupropion before the 12 weeks. Fifteen (11.8\%) subjects changed antidepressants due to poor effectiveness and 19 (15.0\%) due to adverse events. Three (2.4\%) were referred to other clinics, and nine $(7.1 \%)$ were lost to follow up for unknown reasons. Of the 127 subjects treated with bupropion, 54 (42.5\%) reported adverse events (43 [33.9\%] for physical and 19 [15.0\%] for psychiatric adverse events), most commonly irritability ( $n=12,9.4 \%$ ). Of the subjects who reported irritability, four (33.3\%) discontinued bupropion and the others mostly reported spontaneous improvement of irritability. In addition, dizziness ( $\mathrm{n}=11$, $8.7 \%)$, insomnia ( $n=11,8.7 \%)$, decreased appetite $(n=$ $10,7.9 \%)$, anxiety $(n=8,6.3 \%)$, headache $(n=7,5.5 \%)$, drowsiness ( $n=7,5.5 \%)$, nausea/vomiting $(n=5,3.9 \%)$, fatigue $(n=5,3.9 \%)$, AEMS $(n=5,3.9 \%)$, tremor $(n=3$, $2.4 \%$ ), tic ( $n=3,2.4 \%)$, psychotic symptoms ( $n=3$, $2.4 \%)$, nervousness $(\mathrm{n}=2,1.6 \%)$, hypersomnia $(\mathrm{n}=2$, $1.6 \%)$, suicidal ideation $(n=2,1.6 \%)$, seizure $(n=1$, $0.8 \%)$, xerostomia $(n=1,0.8 \%)$, rash $(n=1,0.8 \%)$, and constipation ( $n=1,0.8 \%$ ) were reported. Among them, 19 (35.2\%) subjects stopped bupropion due to adverse events, and in the others, most adverse events were spontaneously resolved.

\section{DISCUSSION}

In this retrospective chart review, bupropion was found to be effective and generally tolerable in children and adolescents with depressive disorder. To the best of our knowledge, this is the largest study to evaluate the effectiveness of bupropion in youth with depression. Improvement was evident in $45.7 \%$ of our subjects. This response rate is similar to the $41 \%$ to $61 \%$ reported for fluoxetine [14]. Although few studies have investigated the effect of bupropion on depressive symptoms in youth, bupropion 
Table 1. Comparison of clinical characteristics between responders and non-responders

\begin{tabular}{|c|c|c|c|c|}
\hline & $\begin{array}{l}\text { Responders } \\
\quad(\mathrm{n}=58)\end{array}$ & $\begin{array}{l}\text { Non-responders } \\
\quad(n=69)\end{array}$ & t or $\chi^{2}$ & $p$ value \\
\hline Age (yr) & $15.0 \pm 2.3$ & $15.5 \pm 2.2$ & -1.235 & 0.219 \\
\hline Sex, boy & $31(53.4)$ & $35(50.7)$ & 0.094 & 0.760 \\
\hline $\mathrm{FSIQ}^{\mathrm{a}}$ & $102.6 \pm 16.7$ & $97.4 \pm 14.5$ & 1.688 & 0.094 \\
\hline SES & & & 4.723 & $0.093^{b}$ \\
\hline High & $0(0)$ & $5(7.2)$ & & \\
\hline Middle & $55(94.8)$ & $62(85.5)$ & & \\
\hline Low & $3(5.2)$ & $5(7.2)$ & & \\
\hline Baseline CGI-S & $4.7 \pm 0.9$ & $4.6 \pm 0.9$ & 0.902 & 0.369 \\
\hline Mean dose (mg) & $188.6 \pm 53.8$ & $174.0 \pm 51.0$ & 1.573 & 0.118 \\
\hline Mean dose per weight $(\mathrm{mg} / \mathrm{kg})$ & $3.0 \pm 1.6$ & $3.0 \pm 1.5$ & -0.086 & 0.932 \\
\hline Family history of psychiatric disorder & $22(37.9)$ & $29(42.0)$ & 0.289 & 0.591 \\
\hline Previous suicide attempt & $14(24.1)$ & $5(7.2)$ & 7.628 & 0.006 \\
\hline \multicolumn{5}{|l|}{ Diagnosis } \\
\hline MDD & $48(82.8)$ & $57(82.6)$ & $<0.001$ & 0.982 \\
\hline Dysthymia & $3(5.2)$ & $11(15.9)$ & 3.726 & 0.054 \\
\hline Adjustment disorder & $4(6.9)$ & $7(10.1)$ & 0.420 & 0.517 \\
\hline Depressive disorder, NOS & $5(8.6)$ & $2(2.9)$ & 1.981 & $0.245^{\mathrm{b}}$ \\
\hline \multicolumn{5}{|l|}{ Comorbidity } \\
\hline ADHD & $20(34.5)$ & $23(33.3)$ & 0.019 & 0.892 \\
\hline ODD/CD & $7(12.1)$ & $12(17.4)$ & 0.702 & 0.402 \\
\hline Anxiety disorder & $9(15.5)$ & $9(13.0)$ & 0.159 & 0.691 \\
\hline Tic disorder & $3(5.2)$ & $10(14.5)$ & 2.979 & 0.084 \\
\hline Obsessive compulsive disorder & $4(6.9)$ & $5(7.2)$ & 0.006 & $1.000^{b}$ \\
\hline Somatoform disorder & $1(1.7)$ & $5(7.2)$ & 2.135 & $0.218^{\mathrm{b}}$ \\
\hline Eating disorder & $2(3.4)$ & $3(4.3)$ & 0.067 & $1.000^{b}$ \\
\hline PTSD & $3(5.3)$ & $1(1.4)$ & 1.432 & $0.331^{b}$ \\
\hline Elimination disorder & $1(1.7)$ & $0(0)$ & 1.199 & $0.457^{b}$ \\
\hline Concomitant non-pharmacological treatment & $9(15.5)$ & $6(8.7)$ & 1.408 & 0.235 \\
\hline Individual psychotherapy & $6(10.3)$ & $3(4.3)$ & 2.960 & $0.141^{\mathrm{b}}$ \\
\hline Family / Group psychotherapy & $0(0)$ & $2(2.9)$ & 1.708 & $0.500^{b}$ \\
\hline Biofeedback & $2(3.4)$ & $2(2.9)$ & 0.031 & $1.000^{b}$ \\
\hline Social skill training & $1(1.7)$ & $1(1.4)$ & 0.015 & $1.000^{b}$ \\
\hline
\end{tabular}

Values are presented as mean \pm standard deviation or number (\%).

FSIQ, full-scale intelligent quotient; SES, socio-economic status; CGI-S, Clinical Global Impressions-Severity; MDD, major depressive disorder; NOS, not otherwise specified; ADHD, attention-deficit/hyperactivity disorder; ODD, oppositional defiant disorder; CD, conduct disorder; PTSD, post-traumatic stress disorder.

${ }^{\mathrm{a}} \mathrm{FSIQ}$ score was available in 47 responders and 55 non-responders.

bFisher's exact test.

has been widely studied for ADHD in pediatric populations [15]. In the Daviss et al.'s study [9], 58\% of subjects with both depression and ADHD and $29 \%$ of subjects with depression only responded to bupropion treatment. In our study, bupropion showed effectiveness both for subjects with and without comorbid ADHD. The effect of bupropion on depressive and ADHD symptoms should be studied further.

The rate of physical adverse events was similar to that reported by the Treatment for Adolescents with Depression Study (TADS), where $32.1 \%$ of fluoxetine- treated youth complained of physical adverse events [16]. Five (3.9\%) of our subjects reported AEMS. This result is in line with the results of previous investigations using SSRIs. In TADS, $3.67 \%$ of subjects showed manic/hypomanic symptoms [16].

Our current study findings should be interpreted in the context of some limitations. First, we conducted a retrospective chart review and therefore could not control for the effect of psychiatric comorbidities or concomitant treatments. Second, we did not have a control group. Third, one of the chart-reviewers was involved in subject 
treatment. Thus, rater bias cannot be excluded although the inter-rater agreement was as high at $\kappa=0.90$. Fourth, diagnoses of depressive and comorbid psychiatric disorders were not based on structured interviews. Fifth, adverse events were based on self-reporting, and could have been underreported.

\section{Acknowledgments}

This research was supported by the Basic Science Research Program through the National Research Foundation of Korea (NRF) funded by the Korea government (Ministry of Science, ICT and Future Planning) (NRF-2015R1A1A3A04001349). The authors have declared no conflict of interest.

\section{Conflicts of Interest}

No potential conflict of interest relevant to this article was reported.

\section{Author Contributions}

Conceptualization: Hyo-Won Kim. Data acquisition: Kukju Kweon, Hyo-Won Kim. Formal analysis: Kukju Kweon, Hyo-Won Kim. Funding: Hyo-Won Kim. Supervision: Hyo-Won Kim. Writing-original draft: Kukju Kweon, Hyo-Won Kim.

\section{ORCID}

Kukju Kweon https://orcid.org/0000-0003-1367-5704

Hyo-Won Kim https://orcid.org/0000-0002-8744-5138

\section{REFERENCES}

1. Rey J. Textbook of child and adolescent mental health [Internet]. International Association for Child and Adolescent Psychiatry and Allied Professionals; 2015 [cited at 2018 July 01]. Available from: http://iacapap.org/iacapap-textbook-of-child-and-adolescent-mental-health.

2. Berigan TR. The Many uses of bupropion and bupropion sustained release (SR) in adults. Prim Care Companion I Clin Psychiatry 2002;4:30-32.

3. Milea $D$, Verpillat $P$, Guelfucci $F$, Toumi $M$ Lamure $M$. Prescription patterns of antidepressants: findings from a US claims database. Curr Med Res Opin 2010;26:1343-1353.

4. Nam B, Bae S, Kim SM, Hong JS, Han DH. Comparing the ef- fects of bupropion and escitalopram on excessive internet game play in patients with major depressive disorder. Clin Psychopharmacol Neurosci 2017;15:361-368.

5. Rush AJ, Trivedi MH, Wisniewski SR, Stewart JW, Nierenberg AA, Thase ME, et al. Bupropion-SR, sertraline, or venlafaxine-XR after failure of SSRIS for depression. N Engl I Med 2006;354:1231-1242.

6. Post RM, Altshuler L, Leverich G, Frye MA, Nolen WA, Kupka RW, et al. Mood switch in bipolar depression: comparison of adjunctive venlafaxine, bupropion and sertraline. $\mathrm{Br} /$ Psychiatry 2006;189:124-131.

7. Arredondo D, Docherty J, Streeter B. Bupropion treatment of adolescent depression. In: 146th Annual Meeting of the American Psychiatric Association; 1993; San Francisco, CA.

8. Glod CA, Lynch A, Flynn E, Berkowitz C Baldessarini RJ. Open trial of bupropion SR in adolescent major depression. J Child Adolesc Psychiatr Nurs 2003;16:123-130.

9. Daviss WB, Bentivoglio P, Racusin R, Brown K, Bostic JQ, Wiley L. Bupropion sustained release in adolescents with comorbid attention-deficit/hyperactivity disorder and depression. J Am Acad Child Adolesc Psychiatry 2001;40:307-314.

10. Andreasen NC, Pressler M, Nopoulos P, Miller D, Ho BC. Antipsychotic dose equivalents and dose-years: a standardized method for comparing exposure to different drugs. Biol Psychiatry 2010;67:255-262.

11. Guy W. Clinical global impression scale, ECDEU Assessment Manual for Psychopharmacology, revised (DHEW Publ. No. ADM 76-338). Rockville, MD:National Institute of Mental Health;1976.

12. Rapoport J, Conners C. Rating-scales and assessment instruments for use in pediatric psychopharmacology researchintroduction. Washington, D.C.:US Government Printing Office Superintendent of Documents; 1985.

13. Goldberg JF, Truman CJ. Antidepressant-induced mania: an overview of current controversies. Bipolar Disord 2003;5: 407-420.

14. Hetrick S, Merry S, McKenzie J, Sindahl P, Proctor M. Selective serotonin reuptake inhibitors (SSRIS) for depressive disorders in children and adolescents. Cochrane Database Syst Rev 2007;(3):CD004851.

15. Ng QX. A systematic review of the use of bupropion for attention-deficit/hyperactivity disorder in children and adolescents. J Child Adolesc Psychopharmacol 2017;27:112-116.

16. Emslie G, Kratochvil C, Vitiello B, Silva S, Mayes T, McNULTY S, et al. Treatment for Adolescents with Depression Study (TADS): safety results. J Am Acad Child Adolesc Psychiatry 2006;45:1440-1455. 